\title{
A LINGUA JAPONESA DOS IMIGRANTES JAPONESES E SEUS DESCENDENTES NO BRASIL
}

\author{
Yoshio Mase
}

I

De que maneira os descendentes de japoneses do Brasil herdaram a língua de seus pais; qual o seu processo de homogeneização e neste processo, quais as interferências que sofre da língua portuguesa: são alguns dos aspectos interessantes, no entanto, não muito explorados a serem abordados em um estudo da língua japonesa utilizada no Brasil. Apesar de dispor de um corpus ainda muito restrito que não me permite conclusões melhor fundadas, gostaria de destacar alguns tópicos que poderão servir de base para reflexões futuras.

Minhas reflexões partem de dados obtidos, em sua maior parte, junto a meus alunos de origem japonesa do Curso de Língua e Literatura Japonesa da USP e junto a japoneses e descendentes de São Miguel Arcanjo e de Ibiúna (cerca de 20 pessoas), do Estado de São Paulo.

Os imigrantes chegaram ao Brasil, trazendo os dialetos de suas inúmeras regiões de origem e foram distribuídos pelas "colônias" de várias partes do Brasil. Na oportunidade, a língua utilizada para a comunicação entre si foi, sem dúvida, o japonês.

O Japão ocupa uma área equivalente à do Estado de São Paulo mas, seus dialetos são vários e variados, não sendo rara a incomunicabilidade pela diversidade que apresentam. A fim de tornar mais fluente a comunicação nas "colônias" japonesas que se formaram no Brasil, esses dialetos seguiram o processo de homogeneização, gerando uma língua comum da colônia.

Que tipo de língua comum seria esse? A primeira hipótese é a adoção da língua padrão do Japão como língua comum, uma vez que os imigrantes aprenderam a língua padrão no seu país de origem e os descendentes que falam o japonês, em sua maioria, também a aprenderam nas escolas de língua japonesa aqui existentes. 
No entanto, a língua comum das "colônias" com que tive contato (São Miguel Arcanjo e Ibiúna), tinha por base, não a língua padrão utilizada no Japão, mas o dialeto comum largamente difundido na sua região ocidental.

Os dialetos japoneses se dividem em:

Dialetos $\left\{\begin{array}{l}\text { 1. do arquipélago japonês } \\ \text { 2. de Okinawa }\end{array}\right.$

No arquipélago japonês, formado por quatro grandes ilhas (Hokkaidô, Honshû, Shikoku e Kyûshû), predominam dois grandes grupos dialetais: o dialeto do leste (grupo ao qual pertence o dialeto de Tóquio, atual capital do país, e que forma a base da língua japonesa padrão) e o dialeto do oeste (grupo ao qual pertencem os dialetos de Quioto, antiga capital do Japão e o de Osaca, a segunda metrópole japonesa).

Uma das razões pelas quais não é a língua padrão, mas o dialeto do oeste japonês que serve de base para a língua comum dos japoneses e seus descendentes no Brasil, é a elevada proporção de imigrantes oriundos da região ocidental do Japão. O número de japoneses do oeste que emigraram ao Brasil atinge 56,7\% (cf. quadro I), número bem superior ao dos emigrantes do leste ou de Okinawa. Há que se notar, ainda, que o dialeto comum do oeste japonês se baseia no dialeto de Quioto e Osaca - dialeto de Kinki - em razão do prestígio dessas duas cidades.

\section{Quadro I}

Regiões de origem dos imigrantes japoneses do Brasil (baseado em dados apresentados em "Imigrantes Japoneses no Brasil", 1964)

\begin{tabular}{|c|c|c|c|}
\hline REGIÃO & leste japonês & oeste japonês & Okinawa \\
\hline$\%$ & 35,0 & 56,7 & 8,3 \\
\hline
\end{tabular}

Segundo os dados obtidos em São Miguel Arcanjo, em sua zona central, vivem cerca de 700 japoneses e seus descendentes, dos quais a maioria é oriunda da província de Kôchi (40\%), seguidos de nascidos nas províncias de Nagano e Hokkaidô, ambos com cerca de 6 a $7 \%$ do total. Mas ao invés de predominar o dialeto de Kôchi, um dos dialetos regionais do oeste japonês, o predomínio é do dialeto comum do oeste, baseado no dialeto de Kinki. 
Eis um exemplo. "É uma escola", em língua padrão (do leste japonês) diz-se /gaQkoR-ㅁa /, no dialeto de Kôchi, /gaQkoR-dja/ e no dialeto comum do oeste, $/ g a Q k o R-\underline{j a} /$. Em situações públicas ou oficiais, usa-se o dialeto comum do oeste $/ g a Q k o R-\underline{j a} /$ e não o dialeto de Kôchi /gaQkoR-dja/.

A língua japonesa dos imigrantes desta região, oriundos do leste japonês, é muito próxima à língua padrão mas, em situações oficiais ou públicas, eles não a utilizam substituindo-a pelo dialeto comum do leste japonês. Em casa, usam comumente a língua padrão mas, em público, empregam o dialeto comum do oeste.

O dialeto comum do oeste predomina no campo da gramática e do léxico da língua japonesa utilizada no Brasil mas o mesmo não se verifica no campo da fonética, inclusive a acentuação.

Entretanto, atualmente, quando a imigração japonesa ao Brasil praticamente se extinguiu, nada nos leva a assegurar que esse dialeto comum do oeste formará a base da língua japonesa comum da "colônia". Caso a língua japonesa padrão continue a ser ensinada nas escolas, este dialeto deve deixar de constituir a língua comum da "colônia", passando a ser usado apenas em família para depois desaparecer do japonês empregado no Brasil. Em seu lugar, aumentarão as interferências da língua portuguesa que tratarei em seguida.

Por outro lado, cumpre notar que desde que a TV foi introduzida no Japão em 1958, os vários dialetos regionais vêm sofrendo um rápido processo de padronização a ponto de, hoje, os velhos dialetos se encontrarem próximos à sua extinção.

III

O fenômeno mais marcante que ocorre na língua japonesa do Brasil é, apesar das diferenças individuais, a forte interferência da língua portuguesa. Tal interferência, naturalmente, se manifesta mais intensamente nas gerações mais novas e se faz notar nos campos da fonética, da gramática e do léxico.

Tomemos o exemplo do léxico. O termo /'oisiR/, com o sentido de "ser saboroso", é utilizado em expressões como /'okasi'wa 'oisiR/ "o doce é gostoso". Para se dizer que "é gostoso massagear os ombros" usa-se: /kata'o monde moraQte 'iRkimocida/

No entanto, no japonês do Brasil, é comum usar /'oisiR/ em ambos os casos, emprego que não se verifica nem na língua padrão nem nos dialetos do Japão. Tal uso se deve à influência do termo "gostoso" do português, que é utilizado tanto no sentido de "ser saboroso", quanto no de "ser agradável". A concepção errônea da correspondência semântica 
unívoca entre /'oisiR/ e "gostoso" gera esse tipo de uso na língua japonesa do Brasil.

Esquematicamente, temos:

Japonês

Português

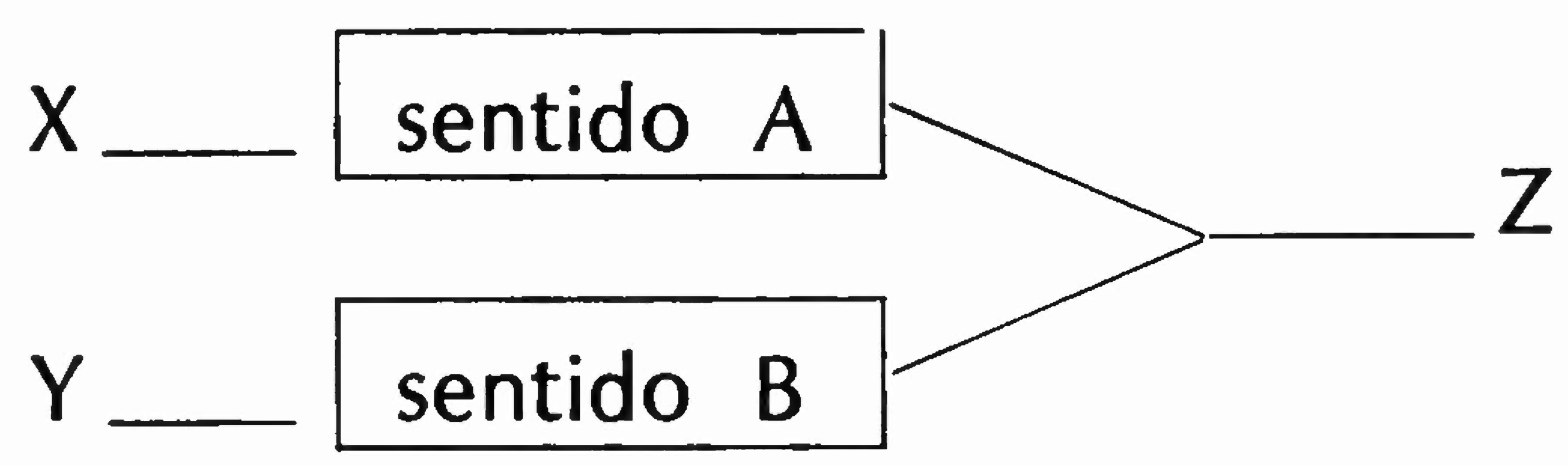

$A$ uma forma linguística $X$ para o sentido $A$ e outra forma $Y$ para $o$ sentido $B$, na língua japonesa, corresponde apenas uma forma linguística $Z$ que abrange os sentidos $A$ e $B$, na língua portuguesa. Por interferência do português, usa-se a forma linguística $X$ também para o sentido de $B$ na língua japonesa utilizada no Brasil.

Exemplos semelhantes são muito frequientes na língua japonesa do Brasil e não vou citá-los mas lembrei que:

1. tal emprego não se verifica em nenhum dialeto do Japão;

2. tais termos são adotados como um léxico comum e largamente empregados no japonês do Brasil.

Ainda no campo do léxico, é muito frequiente a ajaponeização de vocábulos do português e seu uso como gairaigo "vocábulos de origem estrangeira".

Desde antigamente, a língua japonesa assimilou muitos vocábulos de origem estrangeira em seu léxico. No início, importou termos da língua chinesa que foram de tal forma assimilados pela língua japonesa que, hoje, são empregados sem que se tenha mais consciência de sua origem alienígena. Recebem um tratamento especial, não sendo mais considerados gairaigo "termos de origem estrangeira", mas kango "termos de origem chinesa". Nessa medida, são considerados gairaigo "termos de origem estrangeira", os termos introduzidos, em sua maioria, das línguas européias como o inglês, o francês, o alemão, o italiano. O maior número de vocábulos introduzidos é do inglês, já desde antes da II Guerra, número que cresceu ainda mais após a mesma.

A chegada de missionários portugueses por volta do ano de 1600 e a propagação do cristianismo pelo Japão, deixaram alguns gairaigo de origem portuguesa: /kirisuto/ "Cristo", /zibaN/ "gibão", /kaQpa/ "capa", /botaN/ "botão", /sjaboN/ "sabão", /paN/"pão", /koNpeRtoR/ "confeito".

Os gairaigo "vocábulos de origem estrangeira" da língua japonesa de hoje são, como vimos, predominantemente de origem inglesa mas, os do japonês do Brasil são quase todos introduzidos do português, não se 
restringindo apenas aos substantivos mas abrangendo várias categorias gramaticais.

Por exemplo, o pronome pessoal "eu" toma a forma /'joR/ no japonês da "colônia". Seu plural não é /nosu/ nem /noRsu/, provenientes de "nós" do português, mas/'jo-ra/, onde /-ra/ é o sufixo de pluralidade da língua japonesa. Da mesma forma, o pronome "você" é /'oQseR/ no japonês da "colônia" e seu plural é /'oQseR-ra/.

Os substantivos introduzidos do português sobem a números consideráveis. Além dos nomes de objetos que não existiam na língua japonesa à época da chegada dos primeiros imigrantes e daqueles que existiam, mas não eram muito comumente utilizados (Ex.: / hwogoN/ "fogão", /kaRma/ "cama", /koruciRna/."cortina", /kahweR/ "café"), muitos substantivos já existentes na língua japonesa foram substituídos pelos equivalentes da língua portuguesa. Por exemplo: /agu'a/ "água", /bataRta/"batata", /'ahoRzu/ "arroz", /maQsaN/ "maçã", /karune/ "carne", etc.).

Com relação aos verbos, quando o japonês introduz termos de origem inglesa, acrescenta-se /suru/ à forma infinitiva do termo original. Assim, cut "cortar" fica / $k a Q t o-s u r u /$. No entanto, ao introduzir verbos do português no japonês do Brasil, acrescenta-se / suru/ à forma da 3 a pessoa do singular do Presente do Indicativo do verbo original. Por exemplo: /namoRra-suru/ "namorar", /zjaNta-suru/ "jantar". A frequiência muito elevada de uso da 3 a pessoa do singular do Presente do Indicativo dos verbos em português, empregada inclusive para a $2^{\text {a }}$ pessoa, parece ser a causa de se lhe acrescentar /suru/, ao invés de à sua forma do infinitivo.

Em se tratando de adjetivos da língua inglesa usados como gairaigo "vocábulos de origem estrangeira", como por exemplo "colourful", o japonês acrescenta-lhe /da/, ficando/karahuru-da/. O mesmo se dá com os adjetivos do português em geral: /boniRto-da/ "bonito".

No entanto, ao introduzir adjetivos do português, o japonês do Brasil sofre influências do gênero do adjetivo original. Assim:

/'ano 'otoko'wa boniRto-da/ "Aquele homem é bonito"

/'ano musume'wa boniRta-da/ "Aquela moça é bonita."

A distinção do gênero do adjetivo, nesses exemplos, poderia ser induzida pela diferença dos sexos masculinos e feminino de "homem" e "moça", respectivamente, mas tal fenômeno ocorre também com apenas o gênero dos substantivos. Exemplo:

/kuriciRbano maci'wa boniRta-da/ "A cidade de Curitiba é bonita" onde se emprega /boniRta-da/ por se referir à "cidade", substantivo feminino. 
Quando se trata de advérbios, estes são introduzidos com a coadjuvação da partícula $\underline{n i}$ (cf. exemplos a e e $\underline{b}$ ) ou sem ela (cf. exemplos $\underline{c}$ e $\underline{d}$ ).
a) /deQpoisu-ni suru/ "Vou fazer depois."
b) /zireQto-ni ka'eru/ "Vou embora direto."
c) /basutanNci kudasai/ "Dê-me bastante."
d) /maisu kudasai/ "Dê-me mais."

Para responder a perguntas, é frequiente o uso de $s i N, n o N$ em lugar de /hai/ "sim", /' $i R$ 'e/"não", sendo muito comuns suas formas repetidas /siNsiN/, /noNnoN/. No entanto, nas respostas às perguntas formuladas na negativa, com exceção dos imigrantes, seus descendentes sofrem a influência do português e empregam o / hai/ "sim" e /'iR'e/ "não", ao contrário. Cumpre notar que em português, o "sim" e o "não" expressam uma antecipação ou uma asseveração da resposta a ser dada, independentemente da forma em que foi feita a pergunta. Em japonês, ao contrário, expressam a concordância ou não à pergunta formulada. Assim, à pergunta /moR naine/ "já não tem mais", em japonês, teríamos as respostas:

/hai moR nai/ "sim, não tem mais."
/'iR'e mada 'aru/ "não, ainda tem."

No japonês do Brasil, principalmente entre os descendentes, o que se verifica é:

/siN, mada 'aru/ "sim, ainda tem."
/noN, moR nai/ "não, não tem mais."

Quando os alunos conversam comigo em japonês, usam constantemente a forma interjectiva /'aR' $e R /$, originária do português "ah, é?". Da mesma forma, se dá a ocorrência frequiente de /'oQpaR/ "opa", /puRsja/ "puxa".

Apresentei um breve elenco de vocábulos utilizados como gairaigo "vocábulos de origem estrangeira" no japonês do Brasil. Atingem uma monta considerável, comparando-os aos gairaigo provenientes da língua inglesa, bastante numerosos na língua japonesa no seu país de origem. Ocorrem, entretanto, dois fatores que não se verificam no Japão mas são encontrados no japonês do Brasil:

1 - os gairaigo provenientes do português invadem até a área do léxico básico;

2 - o uso do gairaigo está modificando, aos poucos, a estrutura básica da língua japonesa.

A interferência do português é também muito forte na fonética do japonês dos imigrantes e seus descendentes. Aqui, levantarei apenas 
dois de seus aspectos.

Em primeiro lugar, a questão da mora da língua japonesa. O termo sakura "cerejeira" é formado por grupos de consoante (c) e vogal (v): CV.CV.CV. Para o falante da língua japonesa padrão, esse termo é formado por três unidades compostas de CV (sa-ku-ra), com a mesma duração no tempo, chamadas "mora". Sua pronúncia é [sa $\overline{k u r a}$ ]: e não [sa:kura] nem [saku:ra]. É por essa razão que o fonograma japonês tem por base a mora e não o fonema.

Além das moras formadas por $\mathrm{CV}$, há aquelas que são compostas por consoante, semi-vogal e vogal (CSV). É o caso de / $k j a /$ de / $k j a k u /$ "visita", vocábulo formado por 2 moras.

Até aqui, foram apresentados exemplos de termos que a cada mora corresponde uma sílaba. Assim, sakura "cerejeira" é um termo com 3 moras e 3 sílabas, e / $k j a k u$ / "visita", com 2 moras e 2 sílabas.

Há, no entanto, mais três espécies de unidades de mora na língua japonesa que formam 1 mora, isoladamente.

É o caso de $/ R /$, do exemplo a seguir (apresentarei o fonema entre / / e a transcrição fonética, entre [ ] ):

/'obaRsaN/ [oba: $s a N]$ "mulher idosa"

cf./'obasaN/[obasaN] "mulher adulta"

$/ R /$ é o fonema que alonga a vogal precedente pelo tempo de duração de umá mora.

Outro caso é o do som /N/ de [oba: $s a N]$, acima citado. Sua pronúncia apresenta dificuldades aos descendentes de japoneses do Brasil que, frequientemente, articulam-na $[o b a s \tilde{a}]$.

No fim do discurso, pronuncia-se $[N]$ em $[o b a: s a N]$ mas quando o termo aparece em outras posições dentro do discurso, sofre influências do som poscedente:

a. [m] /'obaRsaNmo/ [oba: sammo] "a vovó também."

b. [n] /'obaRsanto/ [oba:santo] "com a vovó"

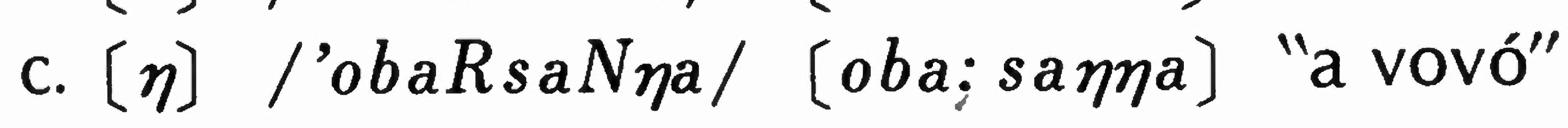

$[N],[m],[n],[\eta]$ são todas nasais e têm a duração de uma mora. Esses sons induzem a unidade de mora $[N]$.

O terceiro caso é o do som $/ Q /$ :

a. /'iQta/ [itta] "foi" cf. /'ita/ [ita] "estava".

O primeiro $[t]$ de $[$ itta] é implosivo e o segundo, explosivo.

O primeiro $[t]$ implosivo tem a duração de 1 mora.

Nos exemplos a seguir:

b. /'iQpa/ [ippa] "uma ala"; 


\section{c. /'iQsa/ [issa] "uma hierarquia militar";}

d. /'iQka/ [ikka] "uma repartição".

O primeiro $[p]$ de $[i p p a]$, o primeiro $[s]$ de $[i s s a]$ e o primeiro $[k]$ de [ikka], têm a duração de 1 mora como o [t] de [itta], são consoantes surdas e sofrem influência da consoante poscedente que induzem a realização da unidade de mora $/ Q /$.

Quanto ao número de sílabas, [oba: $s a N$ ] é dividido em três e [itta], em duas. Mas na língua japonesa padrão, por causa da unidade mora, divide-se em $\underline{o-b a-:-s a-N}$ (5 moras) e $\underline{i-t-t a}$ (3 moras), respectivamente.

Por influência do português, a língua japonesa usada no Brasil, principalmente pelos descendentes, não apresenta moras. A pronúncia se realiza por divisão em sílabas, tornando-a estranha aos ouvidos de um falante da língua japonesa padrão. Ao ensinar a fonética japonesa, constitui uma tarefa muito importante fazer com que os alunos distingam e apreendam a mora.

Gostaria de discorrer, por último, sobre o acento da língua japonesa que, diferentemente da língua portuguesa, se realiza por distinções de altura. Tomando o exemplo da língua japonesa padrão, a cadeia fonética /ame/pronunciada com o $\underline{a}$ alto e o $\underline{m} \underline{e}$, baixo, temos "a chuva", e ao contrário, com o $\underline{a}$ baixo e o $\underline{m e}$ alto, temos "a bala (doce)". A intensidade não constitui traço distintivo da pronúncia japonesa.

$\mathrm{O}$ acento da língua japonesa pode ser dividido em dois grandes grupos: o acento de Tóquio (realizado em Tóquio e demais regiões, constituindo a base do acento da língua japonesa padrão) e o acento de Quioto (realizado em Quioto, Osaca e cercanias). Esses dois tipos de acento, à primeira vista, dão a impressão de serem totalmente opostos. Assim é:

\begin{tabular}{|l|c|c|}
\hline termo & Tóquio & Quioto \\
\hline "flor" & {$[h a \overline{n a}]$} & {$[\overline{h a} n a]$} \\
"outono" & {$[\bar{a} k i]$} & {$[a \overline{k i}:]$} \\
"vermelho" & {$[a \overline{k a i}]$} & {$[\bar{a} k a i]$} \\
\hline Nota: o traço horizontal - indica a tonalidade \\
mais alta da pronúncia. \\
\hline
\end{tabular}

Observando o acento dos descendentes de japoneses do Brasil, nota-se uma vasta complexidade em sua realização. Os imigrantes tendem a conservar o acento do dialeto de sua origem, mas há muitas diferenças 
individuais entre seus descendentes. Quando, os pais são originários de regiões com o mesmo sistema tonal, os filhos praticamente assimilam a mesma acentuação. No entanto, se um dos pais é de uma região com o acento de Tóquio e o outro, com o acento de Quioto, é comum os filhos não apresentarem nenhum acento. Se, por exemplo, o termo ame "chu$v^{\prime \prime}$, é pronunciado $/ \bar{a} m e /$ pelo pai e /a $\overline{m e} /$ pela mãe, o filho não consegue assimilar nem um, nem outro acento. No caso dos alunos do Curso de Japonês da USP, não há um só descendente da terceira geração (sansei) que apresente o acento do japonês. Assim sendo, é certo que a língua japonesa utilizada pelos descendentes perderá uma vez a acentuação.

No entanto, ainda pela observação da língua japonesa usada pelos alunos do Curso de Japonês da USP, pode-se notar, com muita frequiência, a influência do acento de intensidade da língua portuguesa, como segue:

a. /'hana/ "flor" /ha'naga/ ("flor" no caso nominativo).

b. /te'rebi/ "televisão" -/tere'bio/ ("televisão" no caso acusativo).

c. /mu'kasi mu'kasi laru toko'roRni oba'sãna 'ima'siRta/ "Há muito, muito tempo, em um certo lugar, vivia uma velha."

Ao fazer uma projeção sobre o futuro da língua japonesa dos descendentes no Brasil, é forte a possibilidade da interferência do acento de intensidade da língua portuguesa. Esse acento de intensidade não influi na distinção semântica das palavras mas tem a função de separar uma palavra da outra, desempenhando aí, um papel relevante na comunicação.

E com relação ao ensino do acento da língua japonesa, tenho uma visão até pessimista. São duas as suas razões: uma, por ser muito reduzido o número de professores que possam ensinar, de modo sistemático, o acento da língua japonesa; outra, por ser possível a comunicação em japonês, ignorando-se, praticamente, sua acentuação. O acento não desempenha um papel tão essencial na comunicação em japonês, como o é no chinês. Esse fato constitui um dos principais motivos pelos quais não se dá a devida atenção ao ensino sistemático do acento da língua japonesa.

\section{IV}

Essa é, em síntese, uma constatação das principais características da língua japonesa usada pelos imigrantes e seus descendentes do Brasil. Destaquei, inicialmente, a tendência da língua japonesa do Brasil encaminhar para um dialeto baseado no dialeto comum do oeste japonês, enquanto no Japão, os vários dialetos regionais caminham para uma padronização. 
Em seguida, apontei a forte interferência do português sobre essa língua japonesa falada no Brasil, em vários de seus aspectos, fato que ocorre mais intensamente entre aqueles que têm o português como língua materna. É de se supor que tal tendência se torne mais marcante daqui para o futuro, Se voltarmos os olhos para o ensino da língua japonesa no Brasil, esses pontos levantados deverão ser analisados à luz de estudos contrastivos entre o japonês e o português sem o que, acredito, não se obterá grandes resultados.

OBS.: O presente artigo é o resultado de uma revisão da palestra proferida no II Congresso Brasileiro de Estudos Afro-Asiáticos, no dia 04 de novembro de 1986 na USP, sob o título: "A língua japonesa dos descendentes japoneses do Brasil". Cumpre notar que, por se tratar de um artigo escrito, foi aqui suprimida uma grande parte do material colhido junto a japoneses e seus descendentes e gravado em fitas, material este que serviu de base para a apresentação da palestra.

Traduzido por: TAE SUZUKI 